\section{Rare Association of Bilateral Fracture of the Femoral Neck and Slipped Capital Femoral Epiphysis in Osteopetrosis Patient}

\section{Ali Farhat*, Gisela García and Oscar Prado}

Department of Pediatric Orthopedic Surgery, Division Hip Pathology, Children's Orthopedic Hospital, Caracas, Venezuela

\begin{abstract}
We report a rare case of a five-year-old female patient who has Autosomal Dominant Osteopetrosis associated with bilateral fracture of the femoral neck (Salter \& Harris II) and atypical mild slipped capital femoral epiphysis after running and playing, being initially treated conservatively with cast spica for 8 weeks, consolidating the right hip in varus, with decreased mobility ranges and positive Trendelemburg test. When the patient was 7-years-old, it was performed a right valgus femoral osteotomy with a plate screw system plus cast spica for 8 weeks, radiographs showed improved of neck shaft angle, no evidence of avascular necrosis in the affected femoral head, without delayed or non-union in the subsequent visit, integrating rehabilitation and improving ranges of passive and active mobility, as well as gluteal insufficiency. At five year follow up (12-years-old), the patient denies pain and presents good ranges of mobility.

Osteopetrosis is a rare bone dysplasia due to an alteration of osteoclast function in which bone resorption is decreased, resulting in alterations in bone mineral density, frequent fractures and risk of non-union or avascular necrosis, being an atypical case of bilateral femoral neck fracture plus slipped capital femoral epiphysis in a patient with Osteopetrosis. This rare association has never been reported.
\end{abstract}

Keywords: Children; Coxa vara; Femoral neck fracture; Osteopetrosis; Salter and Harris fracture; Slipped capital femoral epiphysis

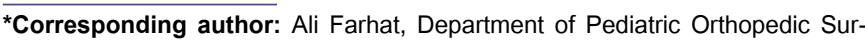
gery, Division Hip Pathology, Children's Orthopedic Hospital, Caracas, Venezuela, Tel: +1 7864509890, Email: orthos36@gmail.com

Citation: Farhat A, García G, Prado O (2019) Rare Association of Bilateral Fracture of the Femoral Neck and Slipped Capital Femoral Epiphysis in Osteopetrosis Patient. J Orthop Res Physiother 5: 044

Received: September 02, 2019; Accepted: September 26, 2019; Published: October 03, 2019

Copyright: () 2019 Farhat A, et al. This is an open-access article distributed under the terms of the Creative Commons Attribution License, which permits unrestricted use, distribution, and reproduction in any medium, provided the original author and source are credited.

\section{Introduction}

Osteopetrosis, also called marble bone disease, Albers-Schonberg disease belongs to the group of bone dysplasia, comprising a clinically and genetically heterogeneous group of conditions that share the hallmark of increased bone density on radiograph. The increase in bone density results from abnormalities in osteoclast differentiation or function and persistence of calcified chondroid material, causing the bone to be dense and brittle [1].

Albers-Schonberg was the first to describe in 1904 in a 26 -yearold patient $[1,2]$. The decrease in osteoclast activity also affects the shape and structure of bone by altering its capacity to remodel during growth. In severely affected patients, the medullary cavity is filled with endochondral new bone, with little space remaining for hematopoietic cells. This abnormality contributes to the brittleness of bone in osteopetrosis.

This rare inherited disorder usually occurs in childhood or adolescence, although its diagnosis is also made at ages between 20 and 40 years.

Several forms of presentation of the disease have been described, but in all, the pathophysiological mechanism is the same, the lack of bone resorption due to a decrease in the number or activity of osteoclasts.

Osteopetrosis has been classified in three clinical forms [3], depending on the severity of its manifestations and the age of onset of the process:

- Childhood or malignant osteopetrosis. It is the most severe type and is inherited in autosomal recessive pattern. Its appearance is early in childhood and is characterized by a severe insufficiency of the bone marrow that usually has a poor prognosis.

- Benign or adult osteopetrosis. It occurs later, in young adults and is inherited with autosomal dominant character. In this variety they have a full life expectancy and there is no severe spinal insufficiency. There is a greater susceptibility to orthopedic pathologies such as fractures, osteomyelitis and early coxofemoral osteoarthritis due to fractures at the level of the femoral neck or slipped of the epiphysis, additionally sometimes some cranial nerves are affected by bone invasion in the holes at the base of the skull.

- Intermediate osteopetrosis. It is less serious than the infant variety and usually affects children under 10 years. It is transmitted recessively and is characterized clinically by cerebral calcifications, renal tubular acidosis and bones with increased density. In this rare variant, a deficiency of the carbonic anhydrase II enzyme, necessary for osteoclastic bone resorption, has been demonstrated.

One of the most serious complications of osteopetrosis is the femoral neck fracture, which has been rarely reported and very few studies about this case are present. Therefore, the optimal management of femoral neck fractures in patients with osteopetrosis has not been clearly defined. No validated treatment guidelines exist $[4,5]$. 
Citation: Farhat A, García G, Prado O (2019) Rare Association of Bilateral Fracture of the Femoral Neck and Slipped Capital Femoral Epiphysis in Osteopetrosis Patient. J Orthop Res Physiother 5: 044.

There is even less information available, when the injury is accompanied by bilateral fractures and Slipped Femoral Capital Epiphysis, related to potential complications including suboptimal healing, avascular necrosis of the femoral head, nonunion, post-traumatic coxa vara, growth arrest, infection, and chondrolysis $[6,7]$.

We report a case of Osteopetrosis (ADO) with bilateral femoral neck fractures (Salter and Harris II) plus slipped capital femoral epiphysis treated in first round conservatively and then surgically as-yet-unreported.

\section{Presentation Case}

A 5-year-old female patient who came to the clinic of Hip Pathology with initial complaints of right painful weight bearing and limp for the last 2 weeks, and then bilateral pain as noticed by her mother after she was running and playing. As a significant antecedent, she got a fracture in the distal phalanx of the 5th right toe at one year of age and a right elbow fracture at 4 years old with conservative treatment. Her physical body appearance at 9 years and 5 months of age was normal with the only evidence of pectus carinatum. Height (51.18”) and weight (65.69 lb.) in average rank, Body Mass Index (BMI) was 17.6 (This indicates a BMI by age, that represent the 68th for normal children at the age of 9 years 5 months which means that she had a healthy weight at that period of evaluation. Dependent gait of crutches, with difficulty, painful to passive mobilization, a slight limitation of abduction and internal rotation. Laboratory blood tests showed 4.53 million cells erythrocyte count per microliter $(\mathrm{mcL})$, Hemoglobin $12.4 \mathrm{~g} / \mathrm{dL}$, increased the levels of erythrocyte sedimentation rate in $35 \mathrm{~mm} / \mathrm{h}$, and slight increased white cell count $(11.6 \mathrm{uL})$ predominantly neutrophils (62.3\%) vs lymphocytes $(28.7 \%)$.

Pelvis radiology and Panoramic x-ray of lower limbs were performed, showing extraordinary bone radiopacity, dense and faint medullary space, thickness of cortical and cancellous bone, bilateral large wedge-shaped fracture of the inferior metaphyseal border of the femoral neck (Red arrow in Figure 1), with inferior subluxation of capital epiphysis, diagnosing Autosomal Dominant Osteopetrosis (ADO), bilateral fracture of the femoral neck (Salter Harris II), along with atypical mild Slipped Capital Femoral Epiphysis (SCFE).
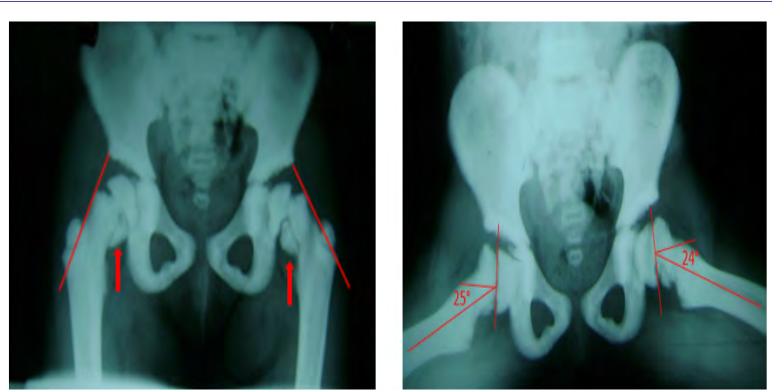

Figure 1: At 5-year-old. Note the extraordinary bone radiopacity, dense and faint medullary space, bilateral fracture of the inferior metaphyseal border of the femoral neck in Anteroposterior (AP) view (Red arrow), with inferior subluxation of capital epiphysis. The line of Klein (Red lines) describes a line along the superior edge of the neck of the femur. It is useful in detecting SCFE. A Southwick angle of $25^{\circ}$ right and $24^{\circ}$ based on femoral epiphyseal-diaphyseal angle difference in a frog-leg lateral $\mathrm{x}$ ray used to measure the severity of a slipped Epiphysis.
Treatment options (In situ pinning vs spica cast), prognosis, and complications were discussed with the parents. They were concerned about the surgery and therefore asked for the patient to be managed conservatively. The patient was initially treated with bilateral long leg hip spica cast ( $30^{\circ}$ of hip flexion and abduction, $45^{\circ}$ knee flexion) for 8 weeks. The other radiographs of spine, thorax and skull (Figure 2) showed increased sclerosis of the bone, vertebral end-plate thickening.

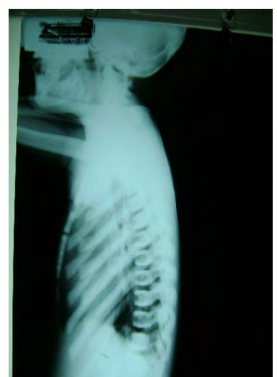

Figure 2: A lateral view of the thoracic spine showing increased sclerosis of the bone in the skull, ribs, and vertebral end-plate thickening.

X-ray at two months (Figure 3) show consolidating of the left fracture, and partial consolidation in the right side with coxa vara $\left(100^{\circ}\right.$ right neck shaft angle vs $120^{\circ}$ left hip) and stabilization of SCFE. Clinically no pain, right hip mobility ranges: Abduction $\left(30^{\circ}\right)$, Adduction $\left(10^{\circ}\right)$, Flexion $\left(85^{\circ}\right)$, Internal rotation $\left(30^{\circ}\right)$, External rotation $\left(40^{\circ}\right)$ and positive right Trendelemburg test. Limited weight-bearing was recommended for a lengthier period.

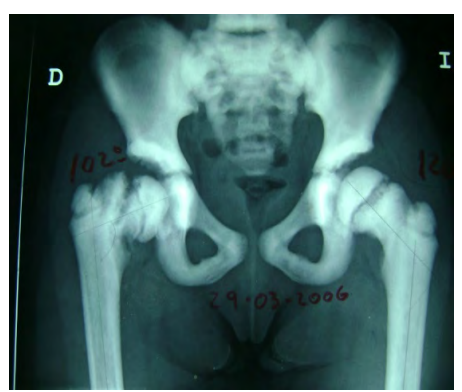

Figure 3: AP radiographs showing Consolidating of left Fractures, and partial consolidation in the right femoral neck with coxa vara $\left(100^{\circ}\right.$ right neck shaft angle vs $120^{\circ}$ left hip) and stabilization of SCFE.

When the patient was 7-years-old, a right valgus subtrochanteric osteotomy of the femur was performed, using a plate screw system for fixation. The patient had to wear a cast Spica for 8 weeks to help to consolidate, improving in the neck shaft angle of $122^{\circ}$ (Figure 4 ).

Subsequent radiographs showed no evidence of avascular necrosis in the affected femoral head, without delayed or nonunion, capacity of remodeling of spherical head and neck femur being congruent in the coxofemoral joint in successive consultations. There was no limp or pain, integrating rehabilitation and improving ranges of passive and active mobility ( $130^{\circ}$ flexion, $45^{\circ}$ abduction), as well as gluteal insufficiency.

At 9-years-old, she was scheduled to have removed osteosynthesis material. At the three years follow up (12-years-old) the child was 
Citation: Farhat A, García G, Prado O (2019) Rare Association of Bilateral Fracture of the Femoral Neck and Slipped Capital Femoral Epiphysis in Osteopetrosis Patient. J Orthop Res Physiother 5: 044.

not in pain or limp, and presented good ranges of mobility, only with shortening of $0.4 \mathrm{~cm}$ right femur (Figure 5 and Figure 6).
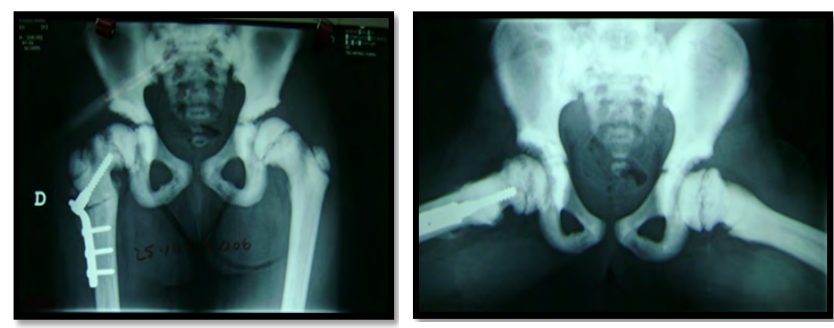

Figure 4: Right valgus subtrochanteric osteotomy of the femur using a plate screw system at 7 years old in the AP and frog-leg lateral radiographs.
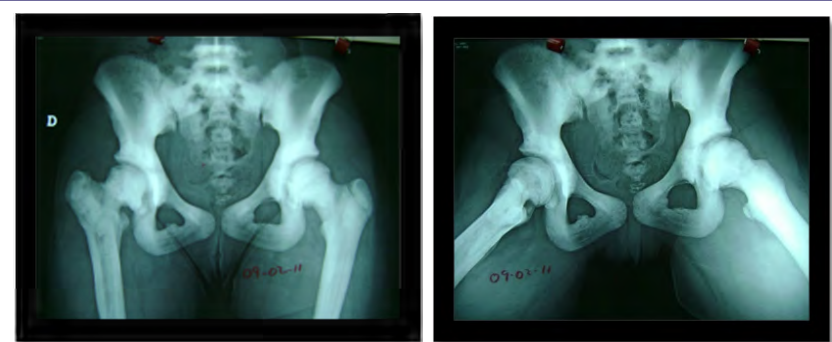

Figure 5: At 12-years-old. AP and frog-leg lateral radiographs. Patient without osteosynthesis material, showed no evidence of avascular necrosis in the femoral head, without delayed or nonunion, and capacity of remodeling of spherical head femur being congruent in coxofemoral joint.

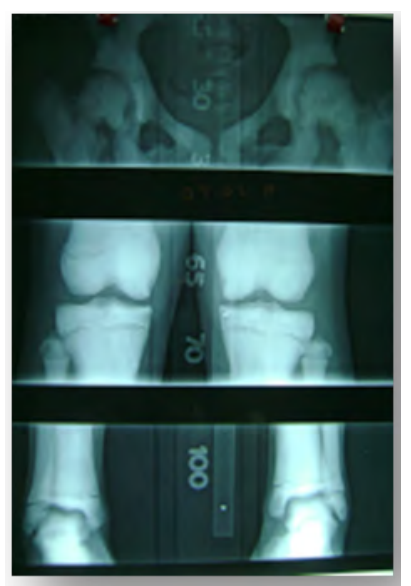

Figure 6: Scanometry of lower extremities with shortening of $0.4 \mathrm{~cm}$ of right femur.

\section{Discussion}

The purpose of this paper is to show a different clinical presentation and the available options to face the natural complications of Osteopetrosis.

We did a review and investigated reports describing association of neck femoral fractures as consequence of Osteopetrosis (ADO) [58], or atypical Slipped Capital Femoral Epiphysis with ADO [9-11].
There was little the literature, and only one publication of the three pathological associations [12], no articles were found related Salter Harris II in proximal femoral fracture in Osteopetrosis, and none being associated with bilateral fracture of the femoral neck and atypical $\mathrm{SCFE}$ in $\mathrm{ADO}$.

Fractures of the proximal third of the femur are rare in children and represent $<1 \%$ of all pediatric fractures. Most injuries result from high-energy trauma, such as a fall from a height or a car accident [4], unlike fractures in patients with endocrinological or metabolic conditions, such as in patients with osteopetrosis, where simple or minimal traumas of very low energy can cause fractures. Events without any traumatic history can trigger a stress fracture, especially in bones that support loads like the femur.

Krieg, et al. [6] support the surgical option as a recommended treatment especially in the neck of the femur, avoiding or decreasing the risks of non-union, coxa vara and subsequent avascular necrosis. The management of stress fractures of the femoral neck in pediatric patients with ADO remains controversial. Surgical and non-surgical treatments present their own challenges.

The Slipped Capital Femoral Epiphysis (SCFE) is a disorder of the child and adolescent hip that can be classified as idiopathic or atypical. Although the vast majority are idiopathic and are reflected in most scientific studies, only a small number of SCFE are atypical, and are those associated with endocrine pathologies such as thyroid disorders, renal failure osteodystrophy, metabolic disorders, osteopetrosis, or undergoing radiation, with little literature in the web, and increasing the risk of being unstable, with subsequent avascular necrosis, and worse prognosis $[13,14]$.

Children presenting with SCFE who are younger than 10 years old or older than 16 years, whose weight is $<50$ percentile for age, or whose height is $<10$ percentile for age should be considered atypical. In this situation it should be mandatory to make a screening and investigate the atypical conditions mentioned above [15]. This is very important to consider as a differential diagnosis, there being no clear and defined guidelines about the management of this group of atypical disorders in the capital femoral epiphysis.

Anatomic factors such as obesity, proximal femoral, retro- version, and a vertical physis are known elements contributing to the mechanical pathogenesis of SCFE. The goals of SCFE surgery are to achieve stabilization, Avoid Avascular Necrosis (AVN), and minimize limitations in function [14].

Kinig, et al., [9] indicate four factors have been postulated in the pathogenesis of slipped capital femoral epiphysis: Increased height of the epiphysis, changes in the inclination angle of the physis, abnormal loading of the growth plate, and insufficiency of the components of the physeal cartilage (collagen and proteoglycan). In the case of patient with Osteopetrosis there is a metabolic defect in the resorption of the bone being prone to multiple microfractures due to defective remodeling increasing the stress and shearing forces across the growth plate that could extend to metaphysis like in our patient. To Abaci, et al., [10] the changing the distribution of weight bearing on the joints is a factor in developing SCFE.

Dharmshaktu, et al., [12] shares a case of a 12-year-old male similar to ours, but in only one side with apparent inferior subluxation of 
Citation: Farhat A, García G, Prado O (2019) Rare Association of Bilateral Fracture of the Femoral Neck and Slipped Capital Femoral Epiphysis in Osteopetrosis Patient. J Orthop Res Physiother 5: 044.

capital epiphysis on right side along with cortical irregularity along neck region. The very presence of decreased neck shaft angle may also increase chances of neck fracture due to higher strain and shear force concentration.

The dense structure of osteopetrosis bone is associated with a low modulus of elasticity, allowing little bony deformation, increasing the risk of tension fractures, coxa vara and degenerative arthritis over time [16-18].

Armstrong, et al., [18] reported in a survey of 172 members of Pediatric Orthopaedic Society of North America (POSNA) being the largest report of femoral neck fracture in patients with Osteopetrosis. 6 patients aged 6 years to 16 years with 7 cases of acute femoral neck fracture were reported. Four of those fractures were treated with closed reduction and internal fixation by using either pins or compression screws without complications. The others 3 were managed nonoperatively with posterior complications like non-union and varo, requiring valgus osteotomy. Our case was in a 5-year-old girl with a bilateral fracture of the inferior metaphyseal border of the femoral neck (Salter Harris II) who secondarily displaced both epiphyses, being the youngest patient with this type of rare complication with unilateral coxa vara that required subtrochanteric osteotomy.

Although coxa vara is a well-known complication of osteopetrosis, there are few reports of its treatment, being difficult to correct surgically the severe deformity because of the hardness and brittle character of the bone substance, increasing the risk of fail and complications. Most of these cases had gradually developed the deformity during early childhood and had become symptomatic with pain and or limping, being treated with a valgus Osteotomy $[17,18]$

A period of non-weight bearing, and bed rest is indicated because of the greater risk of delayed union or nonunion in these patients $[18,19]$. As is pointed out by Gunther, et al. [20] pathogenetically a coxa vara mostly emerges out of a biological insuffciency of the femoral neck or a disturbance of the epiphyseal growth plate, both of which are incapable of handling force loads of everyday activities.

The result of coxa vara and the consequent overgrowth of the greater trochanter bring the hip abductors' sites of origin and insertion closer together, which results in decreasing tension and effciency of gluteus muscles to keep the pelvis stable, resulting in considerable lordosis of the lumbar spine, clinically showing in a positive Trendelenburg's sign with shortening of the affected leg [20], presenting in our patient.

Decreasing the angle of the neck axis can also increase the chance of neck fracture due to a higher concentration of tension and shear force in patients with osteopetrosis [6] and increase the risk of degenerative arthritis over time [16,17,19].

In a study by Palma, et al. [21], bone callus formation was histologically evaluated in a patient with autosomal dominant osteopetrosis $(\mathrm{OAD})$ at different times, revealing normal bone tissue formation at 20 days of a fracture, with normal osteogenesis, with woven bone and occasional cartilage islands with fewer vessels with the characteristics elastics fibers and deformed with scant cytoplasmic osteoclasts. After one year of evolution, a consolidated fracture biopsy was performed, showing primitive bone tissue with lack of lamellar organization, with the absence of osteoclasts. Thus, osteopetrotic fractures do heal, but remodeling does not occur. Moreover, removal of the plate and screw can cause a new concentration of stress corresponding to the screw holes, which can be considered permanent sites of lower resistance, and risk of new fracture.

Little difficulty was experienced with perforation of dense bone in our patient and applying the osteosynthesis, probably because of the mild degree of the disease process. To decrease the risk of thermal bone necrosis [22-24], we always try to avoid the use of a power drill in performing a medullar cervical canal, using manual reamed over a guide wire, and power drill for cortical holes.

Our publication of the bilateral fracture neck femur and SCFE in ADO complicated with coxa vara, is the first report in documented literature, highlighting the importance of categorizing, reporting, and giving alternatives of treatment, the need for close follow-up the patient, and management of these cases with high risk of complications. The use of the screw plate system for the fixation of the proximal femoral valgus subtrochanteric osteotomy proved to be useful in the stability of the proximal femoral third by restoring the neck shaft angle and biomechanical of the hip.

\section{Conflicts of Interest}

No benefits in any form have been received or will be received from a commercial party related directly or indirectly to the subject of this article.

\section{References}

1. Stark Z, Savarirayan R (2009) Review Osteopetrosis. Orph J Rare Diseases 4: 5 .

2. Bollerslev J, Mosekilde L (1993) Autosomal dominant osteopetrosis. Clin Orthop Relat Res 294: 45-51.

3. Palagano E, Menale C, Sobacchi C, Villa A (2018) Genetics of Osteopetrosis. Curr Osteoporos Rep 16: 13-25.

4. Boardman MJ, Herman MJ, Buck B, Pizzutillo PD (2009) Hip fractures in children. J Am Acad Orthop Surg 17: 162-173.

5. Soon K, Kim H (2005) Femoral Neck Fracture in a child with autosomal-dominant Osteopetrosis: Failure of spica cast treatment and successful outcome by internal fixation. J Orthop Trauma 19: 494-497.

6. Krieg AH, Speth BM, Won HY, Brook PD (2007) Conservative management of bilateral femoral neck fractures in a child with autosomal dominant osteopetrosis. Arch Orthop Trauma Surg 127: 967-970.

7. Greene WB, Torre BA (1985) Femoral neck fracture in a child with autosomal dominant osteopetrosis. J Pediatr Orthop 5: 483-485.

8. Steinwender G, Hosny GA, Koch S, Grill F (1995) Bilateral nonunited femoral neck fracture in a child with osteopetrosis. J Pediatr Orthop B 4: 213-215.

9. Kinik H, Polat O, Yildiz Y, Mergen E (2002) Slipped capital femoral epiphysis in osteopetrosis: an unusual case. Arch Orthop Trauma Surg 122: $302-305$

10. Abaci A, Taşcilar ME, Ugurel MS, Yesilkaya E, Coskun ZÜ, et al. (2010) Osteopetrosis and congenital hypothyroidism complicated by slipped capital femoral epiphysis. Endoc Pract 16: 646-649.

11. Cooper J, Sprigg A (1998) Slipped capital femoral epiphysis in a patient with type II autosomal dominant osteopetrosis. Skeletal Radiol 27: 515517. 
Citation: Farhat A, García G, Prado O (2019) Rare Association of Bilateral Fracture of the Femoral Neck and Slipped Capital Femoral Epiphysis in Osteopetrosis Patient. J Orthop Res Physiother 5: 044.

12. Dharmshaktu G, Roy A (2016) Concomitant fracture neck femur and slipped capital femoral epiphysis in a child with osteopetrosis. A rare case report. Intern J Orthop Trauma \& Surg Sciences 2: 401-403.

13. Loder R, Dietz F (2012) What Is the best evidence for the treatment of slipped capital femoral epiphysis? J Pediatr Orthop 32: 158-165.

14. Muchow R (2013) Slipped capital femoral epiphysis: An update on the current management and outcomes. Curr Orthop Pract Vol 24: 612-616.

15. https://www.uptodate.com/contents/evaluation-and-management-of-slipped-capital-femoral-epiphysis-scfe

16. Ganz R, Grappiolo G, Mast J, Matta J, Turchetto L (2017) Technical particularities of joint preserving hip surgery in osteopetrosis. J Hip Preserv Surg 4: 269-275.

17. King R, Lovejoy J (1973) Familial osteopetrosis with coxa vara. A case Report. J Bone Joint Surg 55: 381-385.

18. Armstrong D, Newfield J, Gillespie R (1999) Orthopedic management of osteopetrosis: Results of a survey and review of the literature. J Pediatr Orthop 19: 122-132
19. Landa J, Margolis N, Di Cesare P (2007) Orthopaedics management of the patient with osteopetrosis. J Am Acad Orthop Surg 15: 654-662.

20. Gunther C, Komm M, Jansson V, Heimkes B (2013) Midterm results after subtrochanteric end-to-Side valgization osteotomy in severe infantile coxa vara. J Pediatr Orthop 33: 353-360.

21. Palma L, Tulli A, Maccauro G, Sabetta S, del Torto M (1994) Fracture Callus in Osteopetrosis. Clin Orthop Relat Res 308: 85-89.

22. Pandey R, Panda S (2013) Drilling of bone: A comprehensive review. J Clin OrthopTrauma 4: 15-30.

23. Raj N, Chouhan D, Behera P (2012) Bilateral femoral neck fractures in a child and a rare complication of slipped capital epiphysis after internal fixation-case report. Clin Orthop Relat Res 470: 2941-2945.

24. Togrul E, Bayram H, Gulsen M, Kalaci A, Ozbarlas S (2005) Fractures of the femoral neck in children: Long-term follow-up in 62 hip fractures 36 : $123-130$. 


\section{di}

Journal of Anesthesia \& Clinical Care

Journal of Addiction \& Addictive Disorders

Advances in Microbiology Research

Advances in Industrial Biotechnology

Journal of Agronomy \& Agricultural Science

Journal of AIDS Clinical Research \& STDs

Journal of Alcoholism, Drug Abuse \& Substance Dependence

Journal of Allergy Disorders \& Therapy

Journal of Alternative, Complementary \& Integrative Medicine

Journal of Alzheimer's \& Neurodegenerative Diseases

Journal of Angiology \& Vascular Surgery

Journal of Animal Research \& Veterinary Science

Archives of Zoological Studies

Archives of Urology

Journal of Atmospheric \& Earth-Sciences

Journal of Aquaculture \& Fisheries

Journal of Biotech Research \& Biochemistry

Journal of Brain \& Neuroscience Research

Journal of Cancer Biology \& Treatment

Journal of Cardiology: Study \& Research

Journal of Cell Biology \& Cell Metabolism

Journal of Clinical Dermatology \& Therapy

Journal of Clinical Immunology \& Immunotherapy

Journal of Clinical Studies \& Medical Case Reports

Journal of Community Medicine \& Public Health Care

Current Trends: Medical \& Biological Engineering

Journal of Cytology \& Tissue Biology

Journal of Dentistry: Oral Health \& Cosmesis

Journal of Diabetes \& Metabolic Disorders

Journal of Dairy Research \& Technology

Journal of Emergency Medicine Trauma \& Surgical Care

Journal of Environmental Science: Current Research

Journal of Food Science \& Nutrition

Journal of Forensic, Legal \& Investigative Sciences

Journal of Gastroenterology \& Hepatology Research

Journal of Gerontology \& Geriatric Medicine
Journal of Genetics \& Genomic Sciences

Journal of Hematology, Blood Transfusion \& Disorders

Journal of Human Endocrinology

Journal of Hospice \& Palliative Medical Care

Journal of Internal Medicine \& Primary Healthcare

Journal of Infectious \& Non Infectious Diseases

Journal of Light \& Laser: Current Trends

Journal of Modern Chemical Sciences

Journal of Medicine: Study \& Research

Journal of Nanotechnology: Nanomedicine \& Nanobiotechnology

Journal of Neonatology \& Clinical Pediatrics

Journal of Nephrology \& Renal Therapy

Journal of Non Invasive Vascular Investigation

Journal of Nuclear Medicine, Radiology \& Radiation Therapy

Journal of Obesity \& Weight Loss

Journal of Orthopedic Research \& Physiotherapy

Journal of Otolaryngology, Head \& Neck Surgery

Journal of Protein Research \& Bioinformatics

Journal of Pathology Clinical \& Medical Research

Journal of Pharmacology, Pharmaceutics \& Pharmacovigilance

Journal of Physical Medicine, Rehabilitation \& Disabilities

Journal of Plant Science: Current Research

Journal of Psychiatry, Depression \& Anxiety

Journal of Pulmonary Medicine \& Respiratory Research

Journal of Practical \& Professional Nursing

Journal of Reproductive Medicine, Gynaecology \& Obstetrics

Journal of Stem Cells Research, Development \& Therapy

Journal of Surgery: Current Trends \& Innovations

Journal of Toxicology: Current Research

Journal of Translational Science and Research

Trends in Anatomy \& Physiology

Journal of Vaccines Research \& Vaccination

Journal of Virology \& Antivirals

Archives of Surgery and Surgical Education

Sports Medicine and Injury Care Journal

International Journal of Case Reports and Therapeutic Studies

Journal of Ecology Research and Conservation Biology

Submit Your Manuscript: http://www.heraldopenaccess.us/Online-Submission.php 